\title{
The role of sub-national government and the private sector in future Spatial Data Infrastructures
}

\author{
A. RAJABIFARD, A. BINNS, I. MASSER and I WILLISMSON \\ Centre for Spatial Data Infrastructures and Land Administration \\ Department of Geomatics, University of Melbourne, \\ Victoria 3010, Australia \\ Email: abbas.r@unimelb.edu.au
}

\begin{abstract}
A Spatial Data Infrastructure (SDI) facilitates and coordinates the exchange and sharing of spatial data between stakeholders in the spatial data community. With this objective in mind, countries throughout the world are developing SDIs to manage and utilise their spatial data assets more effectively. These countries are developing SDIs to assist in various kinds of decision-making at different levels of government jurisdictions that have an important impact within their national boundaries. However, current research shows that SDI is understood and described differently by stakeholders from different disciplines and different jurisdictional levels. Therefore, in many cases SDI initiatives remain very much an innovation even among practitioners. There are still uncertainties regarding the benefits and identities of SDIs, particularly in connection with how they evolve over time to meet user needs.
\end{abstract}

This paper reviews and assesses the development of SDIs throughout the world over the past fifteen years and the leadership role of national governments in SDI creation. This assessment is based on the SDI activities of various jurisdictions including AsiaPacific, Australia, North America and Europe and research into the worldwide effects of spatial information clearinghouses. This assessment includes a discussion on emerging trends in SDI development, with particular reference to the increasingly important role played by sub-national governments and the private sector within the framework of SDI development. The paper concludes with a discussion of the implications for future SDI development, including the delivery of a virtual world that has a particular focus on facilitating decision making at a community level within a national context.

Keywords: Spatial Data Infrastructure (SDI), sub-national government, private sector industry, spatial data management.

\section{Introduction}

A Spatial Data Infrastructure (SDI) is an enabling platform for data sharing. It is based on a dynamic, hierarchic and multi-disciplinary concept that includes, people, data, access networks, institutional policy, technical standards and human resources dimensions which aims to facilitate and coordinate the exchange and sharing of spatial data between stakeholders in the spatial data community. An SDI is developed for the purpose of supporting ready access to spatial information to support decision making at different scales for multiple purposes, and is based on partnerships at corporate, local, state/provincial, national, regional (multi-national) and global levels. This enables users to save resources, time and effort when trying to acquire new datasets by avoiding duplication of expenses associated with the generation and maintenance of data and their integration with other datasets.

Sustainable decision-making requires access to accurate information and the tools to analyse and present it. SDI is a crucial means to assemble the best available spatial data to serve a variety of users at 
a political/administrative level throughout an organisation, a nation, regionally, or worldwide. In particular, land and spatial information are considered an infrastructure, with the same rationale and characteristics as roads and communications infrastructure (ANZLIC 1998).

This paper reviews and assesses the spatial information activities of regions including Asia and the Pacific, Australia, North America and Europe in the development of SDIs over the past fifteen years. The assessment concentrates on emerging SDI trends and in particular, the differing roles beginning to be played by national and sub-national governments and the private sector in SDI development in countries within these regions. This leads into a discussion on the implications for future SDI development, including how SDI can be used to help the delivery of a virtual world that facilitates decision making at a community as well as national level.

\section{SDI Development and Dissemination}

Within the concept of an SDI, every nation undertakes to some extent the development of strategic national mapping and spatial data activities to meet their national planning and management needs. The accumulation of these activities over time has resulted in the identification of key linkages between institutional and technical aspects similar in many respects to other forms of infrastructure (such as roads and telecommunications), and occurring in a continuum of development strategies (PCGIAP 1998). As a result of this, many countries started to develop SDI for their own different jurisdictions. Based on this, Rajabifard and Williamson (2002) distinguished and reported on two generations of SDIs, the first and the second generations.

Countries developing the first generation of SDIs from the mid 1980s on any jurisdictional level only had limited knowledge about different dimensions and issues relating to the concept of SDI. These first generation countries including the USA and Australia relied on developing data access relationships, which became the precursor to the development to National SDI initiatives (Rajabifard, et al. 2003).

The major objectives of the SDI initiatives in the first generation as summarized by Masser (1998) were to promote economic development, to stimulate better government and to foster environmental sustainability. Within this first generation, countries designed and developed SDIs based on their specific national characteristics, requirements and priorities. There were few existing experiences in developing SDIs within this generation for countries to learn from and hence one of the major outcomes of the first generation was the documentation of experiences on SDI initiatives, in particular productbased approaches to SDI development (Rajabifard et al. 2003). This included researchers' and practitioners' experiences, status reports on SDI initiatives (such as Onsurd 1998) and other related reports which facilitated most of the SDI development. As explained by Crompvouts et al. (2004), the documentation of SDI experiences not only provided exposure to the developmental strengths and weaknesses of different SDI initiatives and hence a knowledge-base from which to learn and develop initiatives, but it provided social capital to share and foster SDI development in other countries. From this documentation, most countries developed a product-based approach to SDI development driven largely by national governments.

Although organisaitons such as the US Bureaux of the Census in the USA and several academic institutions in the UK developed elements of SDIs in the early 1990's, major SDI development initially centered on initiatives driven by national mapping agencies which have the responsibility for SDI initiatives in their respective countries. This is highlighted by the active participants in the regional SDI development initiative of the Permanent Committee for GIS Infrastructure in Asia and the Pacific (PCGIAP) for example where China's National Bureau of Surveying and Mapping, Geoscience Australia, the Geographic Survey Institute of Japan, the Geographic Survey Institute of Korea, the Survey of India, Indonesia's Bakosutanal, the Royal Thai Survey Department and Philippines NAMRIA are all the national mapping agencies (Williamson et al. 2005). 
It is interesting to note that although these national mapping agencies have the responsibility for SDI initiatives, much of the Spatial Data and SDI activity in these countries is not administered by these agencies. It is administered by sub-national agencies including state or provincial organisations or organisations responsible for land administration, cadastral activities or city administration. This area of administration is focused on large-scale, dynamic, 'people relevant' data (property and socio-economic data) and hence this is where most of the SDI activity exists (Grant and Williamson 2003). In many countries there is still a sharp divide between the activities of these national mapping agencies and their land administration or large-scale counterparts.

The transition to the second generation of SDIs occurred around 2000 when some of the leading countries in SDI development changed strategies and updated the SDI conceptual model (Masser, 2005). This shift was brought about due to the opportunities opened up by the development of the Internet and World Wide Web, which created a much more user oriented SDI concept, one much more effective in maximizing the added value of a nation's spatial information assets, and much more costeffective as a data dissemination mechanism (Masser, 2005). The approach of the second generation focuses on the creation of an infrastructure to facilitate the management of information assets instead of the linkage to existing and future databases. The development model changed from the product-based model seen within countries and sub-national jurisdictions in the first generation to a more processedbased approach, shown in Figure 1.

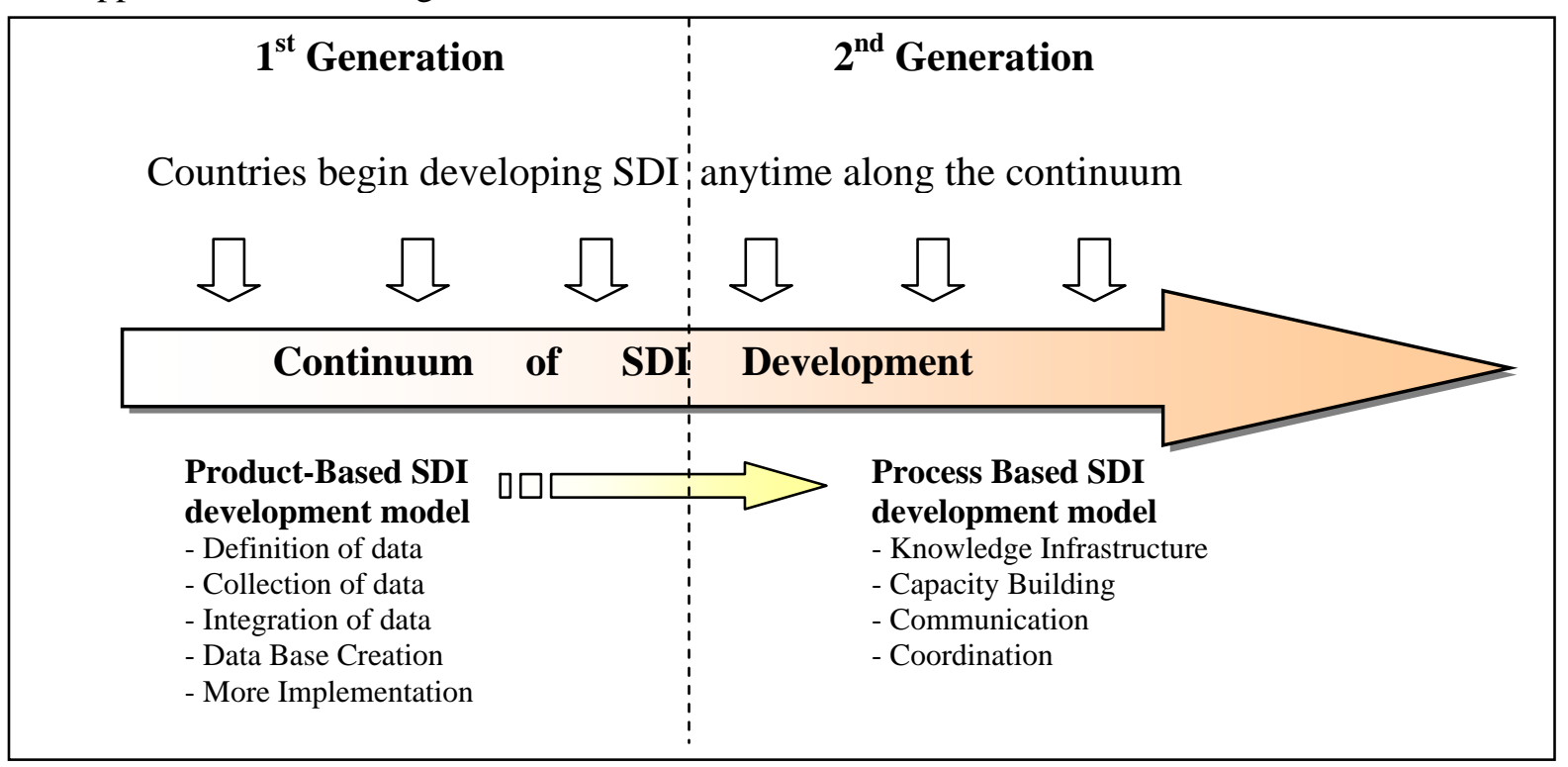

Figure 1. Relationship between the first and second generation of SDI development and the product and process based SDI development models

The product-based SDI model tends to be data-producer and national mapping agency led focusing on data production, database creation and centralisation. The process-based model is driven more by data sharing and re-using data collected by a wide range of agencies for a great diversity of purposes. This model also sees the trend of moving away from the centralized structures of most early SDIs to the decentralized and distributed networks that are a basic feature of the World Wide Web (Rajabifard et al, 2003).

Together with the advances in and lower costs of Information and Communications Technology (ICT), this movement from a product- to process-based SDI model has seen a rapid increase in the number of countries developing SDIs, fostered by the first generations documentation of experiences (Crompvoutes et al. 2004). Figure 1 shows the continuum of SDI development from the first to second generation. 
The second generation of SDI development characteristically falls into two groups: firstly those countries who started to develop an SDI initiative during the period of the first generation and are gradually modifying and upgrading the initiative, and secondly, those countries who have recently decided to design and develop an SDI for their respective countries and/or have just commenced doing so (Crompvoets et al. 2004).

Within the first generation of SDIs, data was the key driver in development and the focus of initiative development. The second generation however is driven by the needs of the users, with focus on the use of data and data applications as opposed to the data itself. This has included the introduction of web services for data sharing and data communication, which are the main technological indicator of the second generation of SDIs through an improved use of data. The second generation also leveraged off the experience, expertise, social capital and the development of clearinghouse systems derived from the first generation. The development of the second generation of SDIs has been relatively quick due to the existence of early prototypes, clarification of initial design issues, increased sharing and documentation of experiences to facilitate implementation, and also due to the concept itself gaining momentum (Crompvouts et al. 2004).

Based on the objectives and strategies of different SDI initiatives from both first and second generations of SDI development, Figure 2 describes the various levels in the SDI hierarchy, how they relate to an organisational pyramid and whether the process or product based model best suits the needs of the jurisdiction (Rajabifard and Williamson 2002). The organisational pyramid includes strategic, management and operational levels which classify the different roles that people play within an organisation. At a multinational (global and regional) level, SDI can be considered similar to the strategic tier of an organisational structure from which a process-based approach to SDI development is most appropriate.

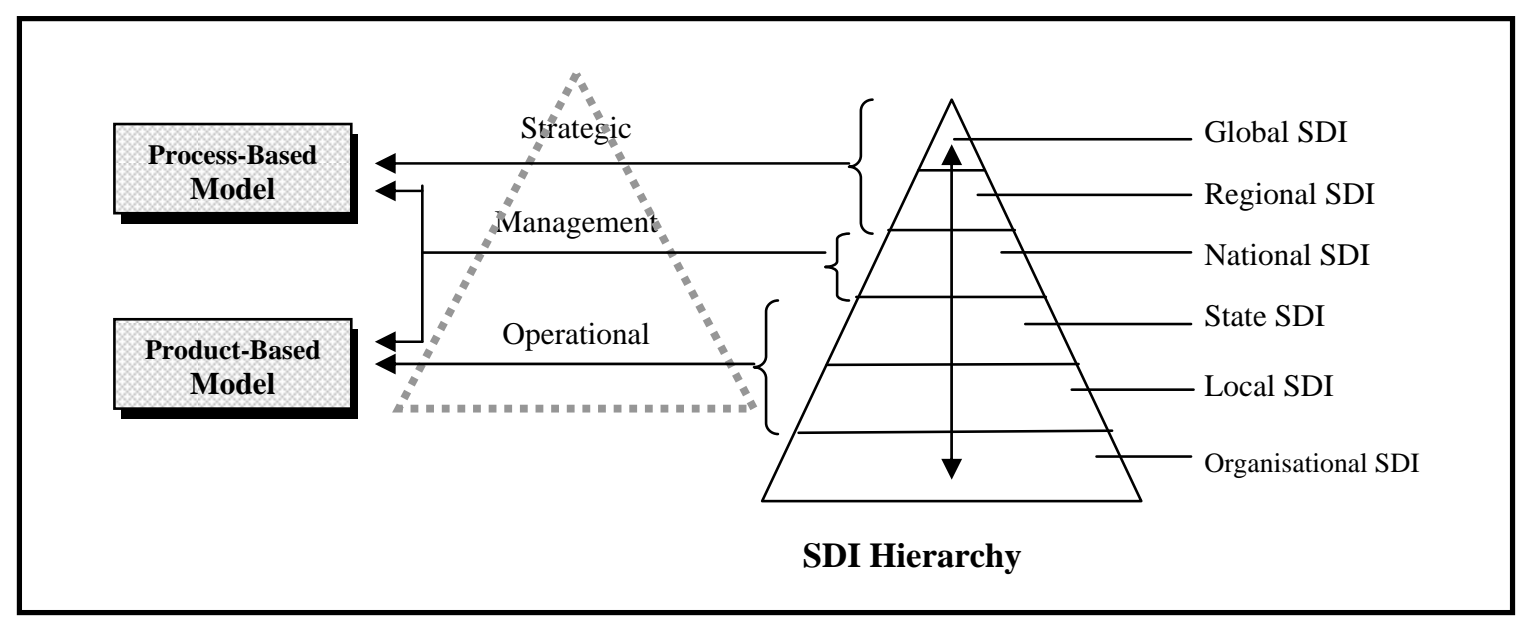

Figure 2. Relationships between SDI hierarchy and different models of SDI development (Rajabifard and Williamson 2002)

An SDI at a national level has resemblance to both managerial and strategic tiers, depending on the political system of the nation. Federated nations generally find advantage in adopting a process-based model for National SDI development due to the federal/state structure of government. Non-federated countries can select between SDI development models to optimize advantage and in some cases, a combined approach can offer most potential for developing effective SDIs (Rajabifard and Williamson 2002).

The sub-national government level of an SDI hierarchy is similar to the operational tier of an organisational structure. These levels produce, collect and manage large scale data which contributes to higher levels of the SDI hierarchy. Due to the system of government in some countries (e.g. federation of states, centralized national government where devolution of power to the States is limited), state 
level SDIs can emulate both management or operational organisation tiers, but as seen in Figure 2, it is suggested that both state and local levels of the hierarchy adopt the product based approach to SDI development. This is due to the fact that most of the data collection and production as well as implementation activities occur at this sub-national level. This also allows the national government of the country to facilitate national-wide communication and coordination of SDI development through a process-based model.

Although SDI development over the past fifteen years has seen three main players emerge, federal/national governments, sub-national governments and the private sector, the role of each has been quite different (Grant and Williamson 2003). As described in Figure 3, initial SDI development was the domain of national governments whose role it was to map and collect small-scale data about a nation (although this was not the case in all countries, with the UK Ordnance Survey for example becoming a semi-independent agency with its own economic drivers for developing SDI). They played both a strategic and operational role in SDI development through a top-down policy development approach. The building of the infrastructure was also seen as a national role, especially within developing countries whose sub-national level of government is generally not as well developed as that of developed countries. The involvement of sub-national governments and the private sector was not as coordinated as that of a national government with generally uncoordinated SDI activity occurring. As policy development came from the national level, there was no real driving role for these two sectors to play in SDI development although there were exceptions, such as in Australia.

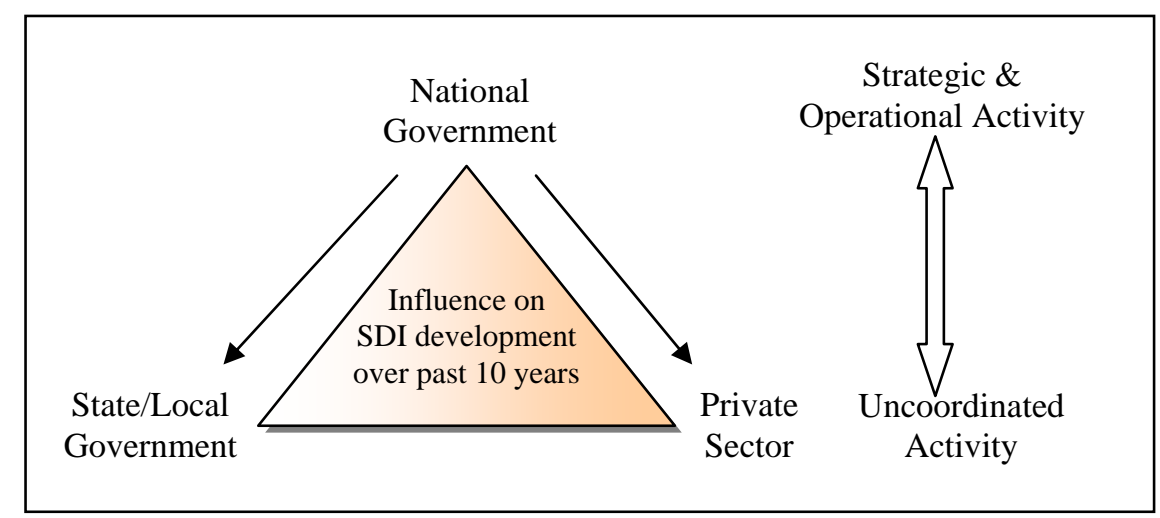

Figure 3. Role of national government, sub-national government and the private sector in SDI development over the past decade

The involvement of these three sectors has enabled the development of the initial concept of an SDI and the role that it can play in streamlining government activities, although the differing political and economic situations of nations has meant that it has not been possible to adopt one simple agreed concept. Overarching policies including national standards and concepts were also created, however these were not always implemented by sub-national governments. This is due to the needs of subnational governments and the private sector beginning to change with the rapid advancement in information and communications technologies and the need for large-scale information to enable more efficient and effective decision-making in the wider community.

\section{Emerging SDI Development Trends and Initiatives}

The later years of the 20th Century saw the rapid development of information and communications technologies (ICT), together with the development of Global Positioning System (GPS) and geographic information system (GIS) technologies which revolutionised the collection, management, presentation and use of spatial information. This technology is now cheaper and more freely available and while the 
national mapping agencies availed themselves of these latest technologies, so did the cadastral and land administration agencies, often to a greater extent.

The result of this technological revolution has been that the large scale land administration sector has been revolutionised. The new technologies have enabled land administration organisations to create digital large scale cadastral data bases and increasingly large scale topographic data bases with many of them in the more developed countries attempting to create large scale virtual representations of their built and natural environments (Williamson et al. 2005; Rajabifard et al. 2005).

However these two developments, small scale national mapping/environmental management and large scale land administration, utility and local government, have evolved and continue to evolve in isolation in many countries, as highlighted previously by the PCGIAP member State representatives. Generally the large-scale level is governed by cadastral and land titling which is often located in a different government department from the small scale national mapping. It is into this environment that the SDI concept, driven by technological advances as well as the potential economic, environmental and social benefits, has evolved over the last decade or so.

Now that many countries and states in federated countries have developed or are developing largescale data sets, the operational role of national mapping agencies is being questioned, unless they reinvent themselves to be custodians for coordinating large-scale data. There is also a role to aggregate and generalize large-scale data to small-scale to link with demographic, natural resource and broad national policy planning.

The diversity of current approaches to SDI development is clearly evident from the findings of the "State of Play" reports on SDI activities in all 32 European countries from the Catholic University of Leuven in Belgium (Spatial Applications Division 2004). The authors of these studies developed a useful typology of SDIs. This typology primarily distinguishes between countries that are national data producer led and those that are not. Within the countries that are led by national data producers, the typology further distinguishes between initiatives that involve users and those that do not. Within the countries that are not national data producer led, the typology distinguishes between initiatives that are based on a formal government mandate and those initiatives for which there was no formal government mandate (Spatial Applications Division 2004).

The "State of Play" studies showed that the development of SDI initiatives in Europe is varied. More than half of the initiatives are led by national data producers and this is particularly the case in the central and eastern European countries that have recently become members of the European Union and the Nordic countries. All the Nordic countries explicitly include data users in the coordination process whereas only a minority of former accession countries make provision for user involvement. The remaining countries have made other arrangements for the coordination of their National SDI activities. In Germany for example, a government interdepartmental body has been formally mandated to create a National SDI which is now operational. In the Netherlands on the other hand, a national GI association has been encouraged by the government to take the lead, and it has succeeded in developing an operational National SDI. These examples show the different paths that can be followed in the creation of an SDI and demonstrates that there is not one simple solution to SDI development.

Within the US, following criticisms by the US Government Audit Office (2003, 2004) and others about the interrelationships and perceived duplication of effort among its initiatives, the Federal Geographic Data Committee (FGDC) was prompted to clarify its position with respect to initiatives such as the Geospatial One Stop (GOS) and also consider its future directions. GOS is an eGovernment priority which implements the basic elements of the NSDI by providing an Internet portal to facilitate data sharing and encourage decision support across all jurisdictional levels of the country. The FGDC has set up its own Future Directions Project to craft a strategy and implementation plan to further the development of the NSDI. Following consultations with many of the stakeholders involved, it has produced a document (FGDC 2004) that identifies three overarching themes as the context for its future target goals and strategies. The first of these themes 'Partnerships with Purpose' sets out a governance structure that includes representatives of all stakeholder groups to guide the development of the NSDI. 
The initial target goals and actions relating to this theme suggest that the FGDC is considering a radical departure from its previous practices.

Although national governments will continue to play a coordinating role within SDI development, Sub-national governments and the private sector are taking on the operational role within SDI development due to the increasing need for maintained and up-to-date large-scale people relevant spatial information.

The case of Alberta, Canada is an interesting example of the way that the roles of sub national governments and the private sector are changing. In 1996 Alberta Environment Protection, a state of Alberta government agency, decided that its core business was not that of updating, storing and distributing digital base maps and hence set up a new company, Spatial Data Warehouse (SDW), to carry out these tasks. SDW is an Alberta registered not for profit company owned by a consortium of agencies from different levels of government and the utility sector. However the expertise and resources required to reengineer the SDW into the Alberta SDI and make it viable over the long term far exceeded the original expectations and commitments of the SDW participants. In order to make data increasingly available, accessible, accurate and affordable, SDW needed expertise, technology, financing, legal skills, marketing, management and business acumen, something which was difficult to coordinate and achieve consistently across the consortium of different agencies within SDW. Hence, SDW decided that they did not have the expertise or the resources to re engineer their business and selected AltaLIS Ltd, a private sector company to carry out this work (SDW 1998).

AltaLis and SDW prepared a detailed business plan for its operations and signed a long term Joint Venture Agreement in December 1999, forming a government/private partnership to help develop Alberta's SDI. This enabled them to implement new pricing and licensing options as well as to introduce a Value Added Service Providers Agreement. AltaLis's activities revolve round the maintenance and distribution of four primary provincial data sets: urban cadastre, rural cadastre, topographic mapping $(1: 20,000)$ and small scale mapping at scales of 1:250,000 and above with the government of Alberta retaining the copyright to this SDI framework data (www.AltaLis.com). The development of a partnership between government and the private sector enabled more modern technologies and processes to be used in the development of Alberta's SDI, making digital mapping more accessible, affordable and useful to Albertans as well as creating a self-sustaining, long-term SDI initiative (SDW 1998). The removal of traditional government funding has also meant that the SDI initiative, through SDW and AltaLIS, has to be responsive to user needs, as it is now the users who fund the continuance of Alberta's SDI, an aspect of SDI development that is beginning to be seen in other jurisdictions, such as in the State of Victoria, Australia.

Another case, that of the United Kingdom, illustrates the way in which thinking about SDIs has evolved over the last fifteen years. Initially the government rejected the recommendation contained in the Chorley report on Handling Geographic Information (Department of the Environment 1987) to set up an independent national Centre for Geographic Information with strong links to government to promote the use of geographic information technology. Nevertheless, a consortium led by Ordnance Survey Great Britain launched the National Geospatial Data Framework (NGDF) in 1996. During the latter part of 2000 the NDGF Board asked for a strategic review of NGDF. The conclusion of this review was that the NGDF should cease to exist as an entity during 2001 (Hadley and Elliott 2001) and that the Association for Geographic Information should take over all the NGDF existing operations. Alongside these developments has been the emergence of regional SDI strategies within the United Kingdom that has been stimulated by the devolution of some powers to elected regional assemblies in Scotland, Wales and Northern Ireland (Masser 2005).

National coordination in Australia is being provided by ANZLIC - Australia's spatial information council, through an overarching strategic framework but it is at the state and local government level, in cooperation with the private sector where SDIs are being built. Australian industry has also created the Australia Spatial Information Business Association (ASIBA), a body whose primary purpose is to represent industry views to government and to promote adoption of spatial information products and services. A representative of ASIBA is also a member of the ANZLIC standing committee, the national 
coordination body for the development of the ASDI ensuring a direct voice for industry in SDI development (Clarke et al. 2003).

State based governments in Australia (which is a federation of states) are moving forward in relation to creating policies and initiatives that aid in the development of SDIs and utilize the expertise and cooperation of the private sector. Within the State of Victoria for example, the framework cadastral, topographic and network datasets are maintained by the private sector through service agreements between the government and individual organisations. The development of the Spatial Smart Tag by Geomatic Technologies in conjunction with the Victorian government, Microsoft and the Public Sector Mapping Agency (PSMA) also demonstrates the linkages between government and the private sector. The Spatial Smart Tag is a new tool that enables desktop users to quickly and easily access spatial information. The tag is installed on a Microsoft Office XP or Office 2003 desktop to enable verification of property addresses, look up postcodes, get map references, view maps and obtain property reports. This is done through simply typing in an address through Word or Excel and selecting a spatial smart tag menu option (GT, 2004). The Spatial Smart Tag has the capability to revolutionise the way in which spatial data is used in everyday situations as it can be used by those who have no prior knowledge of complex spatial systems. This type of development between the private sector and governments will aid in developing an SDI that is widely used as it is focused on business and user needs. The Smart Tag is a tool which is built on the framework of the State's SDI, accessing information and presenting it to the user in a cost-effective and timely manner for a specific purpose, in effect helping to create the first small step in moving towards the ultimate goal of a Virtual Jurisdiction.

The development of policies relating to pricing and access of spatial information and nonrestrictive data policies being developed within SDIs are also beginning to grow the private industry within many nations. A study prepared by PricewaterhouseCoopers in 2002 (in Weiss 2002) on the weather risk management industry within the US and Europe found that the industry is booming within the US (9,696 million USD in contract value in 5 years ending March 2002) compared to Europe (721.3 million USD in the same 5 years). This activity within the US has resulted in a tenfold difference in the number of firms, revenue and job creation within the sector. The reason given for the difference in market size between the US and Europe (given that their economies are approximately the same size) is the restrictive data policies of a number of European national spatial information and meteorological services (Weiss 2002).

The current trends and development within SDIs have shown that the roles of the three major players are changing to meet the new large-scale focus of many SDIs, especially in the developed world (Figure 4). The previous influence of national governments at both strategic and operational levels has diminished, although there is still a strong case for a strategic national government role in SDI through coordination. This can be seen in Europe through the development of the proposal for a legal Directive establishing a European SDI currently before the European Parliament as well as within the federated system of governance in Australia.

The operational level of SDI that in the first generation was undertaken by national governments has now moved to the sub-national government level. It is at this level that largescale land administration data is produced (most common form of spatial data is land related

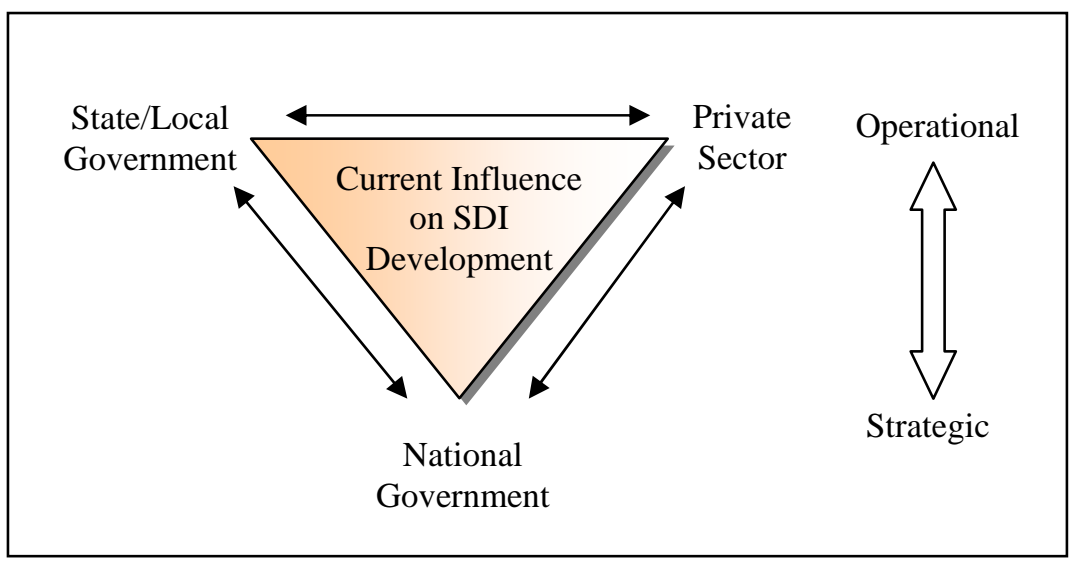

Figure 4. Current role of national government, sub-national government and the private sector in SDI development particularly in developed countries 
data). This aids in collecting land taxes, land use planning, the operation of land markets, road and infrastructure development and day-to-day decision making in order to meet sustainable development objectives. The private sectors operational role has also increased as seen in the examples of Alberta, Canada and the formation of ASIBA within Australia. They are leading the drive for greater access to 'people-relevant' data that is utilized to effectively undertake their role within society.

The flow of information between the three main players has also changed, as can be seen in Figure 4. Building of infrastructure generally occurs at a sub-national, bottom-up level with the national government providing the overall framework in which such infrastructure can operate (although national governments do play some role in infrastructure building). This is what is beginning to occur within the development of SDIs, particularly in Australia and the United States. Communication now flows between these three players, rather than from a top-down national government approach.

\section{SDI Continuum}

As the examples above show, the process of SDI development is a continuously evolving one with a continuum of development across all countries. Figure 5 shows the SDI continuum through the development of the first and second generations of SDIs, the change from a product to process based model, and the changing role that national government, sub-national government and the private sector play, with an indication of the different groups of countries developing SDIs also shown. Most countries are at some stage of the continuum, as illustrated in Figure 5. Mainly developed countries (e.g. Australia, USA, Canada, Japan) initiated the first generation of SDI development through a product based SDI development model with national government as the major influence. Some of the emerging economic (e.g. Malaysia, Korea) and developing (Indonesia, Nepal) countries began to also create SDI initiatives as influenced by developed countries. Countries either continue along this path of development, or have moved on to the second generation of SDI development as a result of a better understanding of the nature and processes involved. This generation has seen a move towards a process based SDI model largely influenced by national and sub-national (local/state) governments and the private sector. SDI development amongst countries increased dramatically around the year 2000 with most actually falling into the second generation of development.

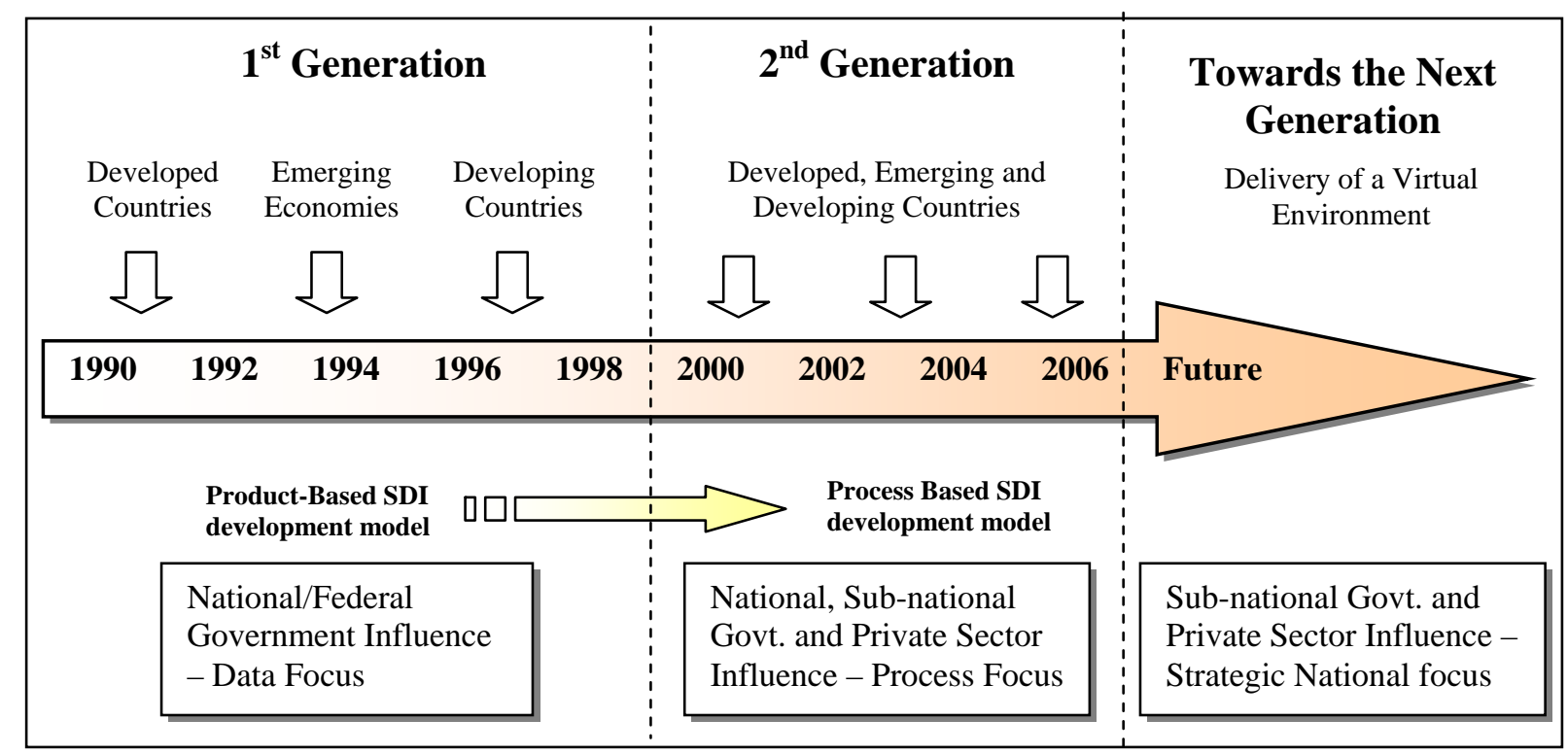

Figure 5. Continuum of SDI Development based on the first and second generations of SDI 
The current situation of SDI development within a country can be placed on the SDI continuum. Countries only now beginning to develop SDIs are often still influenced by national governments and begin through small scale SDI development. This is generally the case with developing countries. As a country tackles broader capacity building and development issues, they are influenced more by largescale "people relevant" data - such as in emerging economies. This means that sub-national governments begin to assert more influence on SDI development. Developed countries have also begun to tackle issues of sustainable development and "triple-bottom line" objectives in which large-scale decision making data is of the utmost importance. The private sector within such countries has also grown substantially to the point where they are beginning to utilize, create, maintain and influence the implementation of SDIs.

\section{Future SDI Development - Towards the Next Generation}

In order to address today's information needs, the role of the traditional SDI needs to be adjusted as highlighted by Radwan et al. (2005). There is a need for a service-oriented infrastructure in which citizens and organisations can rely for the provision of required services. This goes beyond current first and second generation SDIs of a data discovery and retrieval nature.

This translates into the future focus for spatial information managers on the delivery of a virtual world which facilitates decision making at a community level within a national context. This requires integration of the natural and built environmental data sets and the need for an SDI that facilitates this integration. The technology exists to create this virtual world but this is not enough in itself without the sustained input from both data producers and users (CRC-SI 2005).

The benefits of a virtual world include the representation of feature-based structures of the world as well as the administration and institutional aspects of such features, enabling both technical and institutional (e.g. policies) aspects to be incorporated into decision-making. It is this aspect of research that is often identified as more challenging than complex technical issues (Rajabifard et al. 2005). As part of work being undertaken by EuroGraphics - the Association of Europe's National Mapping Agencies, Land (2005) also recognizes the need to focus on institutional rather than just technical challenges in building SDIs and delivering interoperable information.

The vision of a virtual world however is overly simplistic and presents many challenges, with one of the major challenges being the creation of an SDI to support the vision. Whilst most SDI authorities will agree that SDIs should be user driven, there is little discussion on the spatial information vision for each country or what sort of ICT enabled society we wish to be. Unless an agreement on a spatial information vision for each country (or jurisdiction) is made, it is almost impossible to create an appropriate SDI vision. Therefore the first challenge is to clearly describe and articulate the type of society an SDI should support.

Some other challenging questions for future SDI development are posed by the need for a high degree of multilevel stakeholder participation in SDI implementation. The scale and complexity of these operations in countries with both a large land mass, large population and heavily decentralized governance structure, such as the US, is massive given that more than 80,000 public bodies alone are involved in some way. This task is made even more difficult by a governance model that is based largely on consensus building and the extent to which coordination bodies such as the FGDC in the US and ANZLIC in Australia lack the powers to enforce their strategies or to impose sanctions on unwilling participants.

It must also be recognised that the vision of a bottom up SDI, driven more by sub-national governments, differs markedly from the top down one that is implicit in much of the current SDI literature. While the top down vision emphasises the need for standardisation and uniformity the bottom up vision stresses the importance of diversity and heterogeneity given the very different aspirations of the various stakeholders and the resources that are at their disposal. Consequently the challenge to those involved in future SDI implementation is to find ways of ensuring some measure of standardisation and 
uniformity while recognising the diversity and the heterogeneity of the different stakeholders. This will involve a sustained mutual learning process on the part of all those involved (Masser 2005).

Data sharing among the participants on an unprecedented scale will also be needed for SDIs to become fully operational and effective in practice. This is likely to require considerable changes in the organisational cultures of the participants. Onsrud and Rushton (1995) define the issues involved in data sharing in the following terms:

'Sharing of geographic information involves more than a simple data exchange. To facilitate sharing, the GIS research and user communities must deal with both the technical and institutional aspects of collecting, structuring, analysing, presenting, disseminating, integrating and maintaining spatial data.'

Some of the problems involved have been highlighted in Wehn de Montalvo's (2003) study of spatial data sharing perceptions and practices in South Africa from a social psychological perspective. This study utilises the theory of planned behavior as a framework for analysis. This theory suggests that personal and organisational willingness to share data depends on attitudes to data sharing, social pressures to engage or not engage and perceived control over data sharing activities of key individuals within organisations. The findings of Montalvo's quantitative analysis generally bear out the relationships postulated in this theory and give valuable insights into the factors that determine the willingness to share spatial data. They also show that there is only a relatively limited commitment amongst those involved to promote data sharing in high profile initiatives.

\section{Conclusions and Recommendations}

As this paper has highlighted, there are a number of important issues related to any level of SDI development from design to technical, socio-technical, institutional and financial perspectives. There are also a number of other issues identified which do not fall into these categories. These issues are discussed in relation to options for a jurisdictional and institutional framework or enabling platform for SDI development. What is important is that these issues should be considered in the long-term in order to achieve sustainable and ongoing development of SDIs.

As a result, some SDI development initiatives exhibit characteristics of different SDI development models, or of being in a transitional stage - developing a more process-based approach while having product-based origins. This has begun a process of looking beyond a single focus for strategic SDI development to the broader issues contributing to the context of any SDI initiative. Therefore, understanding of the relationships between different SDI jurisdictions, knowing more about SDI development issues and knowing about the potential and applicability of each SDI development model are important for effective SDI development and drive the flexibility required in the second generation of SDI development.

Whatever happens, every country will increasingly require some form of strategic National SDI coordination (and leadership). Whether this is a re0engineered national mapping agency or a consortium of the major large-scale producers, there will always be the need for a nation wide SDI focus at the national political level. Current examples and drivers of this national strategic role include counter terrorism and emergency response, natural resource management across jurisdictions (such as salinity and water issues) and development of oceans policy, especially within countries who rely on the oceans as a major source of food.

There has however been a movement away from national small-scale data to more people relevant large-scale information, generally derived at a sub-national level. The development and availability of this people relevant data together with the creation of an enabling platform or "Virtual Jurisdiction" as described within the third generation of SDI development is creating new opportunities for greater private sector involvement in SDI development. There is the need to build an enabling platform which will need to be the primary domain of sub-national governments, creating access to fundamental largescale datasets across linked jurisdictions. 


\section{Acknowledgments}

The authors wish to gratefully acknowledge the Centre for Spatial Data Infrastructures and Land Administration at the Department of Geomatics, the University of Melbourne for assisting and supporting the preparation of this paper and the associated research. However, the views expressed in the paper are those of the authors.

\section{References}

ANZLIC 1998, Discussion paper: Spatial Data Infrastructure for Austarlia and New Zealand.

Clarke, D., Hedberg, O. And Watkins, W. 2003, Development of the Australian Spatial Data Infrastructure, Chapter 8, in Developing Spatial Data Infrastructures: from Concept to Reality, Williamson, I., Rajabifard, A. \& F. Feeney, M-E. (Eds), Taylor \& Francis, UK.

CRC-SI 2005, Know, think, communicate: key elements for Virtual Australia, A discussion paper, Thomson, B. and Chan, T.O. (Eds), Cooperative Research Centre for Spatial Information, Australia.

Crompvoets, J., Rajabifard, A., Bregt, A. And Williamson, I.P. 2004, Assessing the worldwide development of national spatial data clearinghouses, International Journal of Geographic Information Science, 18(7), 1-25.

DEPARTMENT OF ENVIRONMENT 1987, Handling geographic information: report of the committee of enquiry chaired by Lord Chorley, London: HMSO.

FEDERAL GEOGRAPHIC DATA COMMITTEe (FGDC), 2004, NSDI Future directions initiative: towards a national geospatial strategy and implementation plan, Reston VA: Federal Geographic Data Committee. Available online at: www.fgdc.gov (accessed 19 March 2005).

Grant, D. AND Williamson, I. 2003, 'Chapter 7: State SDI Initiatives’, in Developing Spatial Data Infrastructures: From Concept to Reality, Williamson, I., Rajabifard, A. \& F. Feeney, M-E. (Eds), Taylor and Francis,UK.

GOVERnMENT AUDIT OfFICE, 2003, Geographic information systems: challenges to effective data sharing, Testimony before the Sub Committee on Technology, Information Policy, Intergovernmental Relations and the Census, Committee on Government Reform, House of Representatives, Washington DC: Government Audit Office.

GOVERnMENT AUDIT OFFICE, 2004, Better coordination and oversight could help reduce duplicative investments, Testimony before the Sub Committee on Technology, Information Policy, Intergovernmental Relations and the Census, Committee on Government Reform, House of Representatives, Washington DC: Government Audit Office.

GT 2004, The Spatial Smart Tag, Presentation by Geomatic Technologies, November 2004.

Hadley, C., AND L. ElLiotT, 2001, National Geospatial Data Framework (NGDF): the UK model. Available online at: www.gisdevelopment.net/policy/gii/gii0004pf.htm (accessed 20 June 2004)

LAND, N. 2005, EuroGeographics - Underpinning Europe’s Spatial Information Infrastructure: Obstacles and Solutions, In Global Spatial Data Infrastructure 8 and FIG Working Week Conference, 14-18 April, Cairo Egypt. 
MAsSER, I. 1998, The first Generation of National Geographic Information Strategies, In Proceedings of Selected Conference Papers of the Third Global Spatial Data Infrastructure Conference, November 1998, Canberra.

MASSER, I. 2005, GIS worlds: creating spatial data infrastructures, Redlands CA ESRI Press.

ONSRUD, H. AND G. RUSHTON, 1995, Sharing geographic information, In Sharing geographic information, H. Onsrud and G. Rushton (Eds), Piscataway NJ: Centre for Policy Research, Rutgers University.

ONSRUD, H.J. (1998). Survey of national and regional spatial data infrastructure activities around the globe, In Selected Conference Papers of the 3rd Global Spatial Data Infrastructure Conference, 17-19 November 1998, Canberra, ANZLIG.

PCGIAP (1998). A Spatial Data Infrastructure for the Asia and the Pacific Region, (PCGIAP Publication No. 1), Canberra.

PRICEWATERHOUSECOOPERS, 2002, The weather risk management industry: survey findings for November 1997 to March 2002, Prepared for the Weather Risk Management Association, June 2002. Available online at: www.wrma.cyberspace.com/library/public/ file345.doc (accessed 19 March 2005)

Radwan, M., Onchaga, R. And Morales, J. 2005, The Design Requirements for Serviceoriented Spatial Information Infrastructures, In Global Spatial Data Infrastructure 8 and FIG Working Week Conference, 14-18 April, Cairo Egypt.

RAJABIFARD, A., BinNs, A. AND Williamson, I. 2005, Development of a Virtual Australia Utilising an SDI Enabled Platform, In Global Spatial Data Infrastructure 8 and FIG Working Week Conference, 14-18 April, Cairo Egypt.

Rajabifard, A., Feeney, M.E., Williamson, I. AND Masser, I. 2003, National spatial data infrastructures. In Developing spatial data infrastructures: From concept to reality, Williamson, I., Rajabifard, A. and Feeney (Eds), Taylor and Francis, UK.

Rajabifard, A. AND Williamson, I. P., 2002, 'Spatial Data Infrastructures: an initiative to facilitate spatial data sharing', In Global Environmental Databases-Present Situation; Future Directions - Volume 2, International Society for Photogrammetry and Remote Sensing (ISPRS-WG IV/8), GeoCarto International Centre, Hong Kong.

SpATIAL ApPLICATIONS Division 2004, Spatial data infrastructures in Europe: state of play Spring 2004. Available online at: http://inspire.jrc.it/state_of_play.cfm (accessed 10 March 2005)

Spatial DATA WAREhouse (SDW), 1998, Alberta spatial data infrastructure initiative: an overview, Calgary: Spatial Data Warehouse, Available online at: http://www.altalis.com/downloadables/news1998_04_00.pdf (accessed 12 October 2005)

WeHn DE Montalvo, U. 2003, Mapping the determinants of spatial data sharing, Aldershot: Ashgate.

WeIss, P. 2002, Borders in Cyberspace: Conflicting Public Sector Information Policies and their Economic Impacts, Summary Report, February 2002.

Williamson, I., Grant, D. AND RAJABIFARD, A. 2005, Land Administration and Spatial Data Infrastructures, In Global Spatial Data Infrastructure 8 and FIG Working Week Conference, 14-18 April, Cairo Egypt. 


\section{University Library}

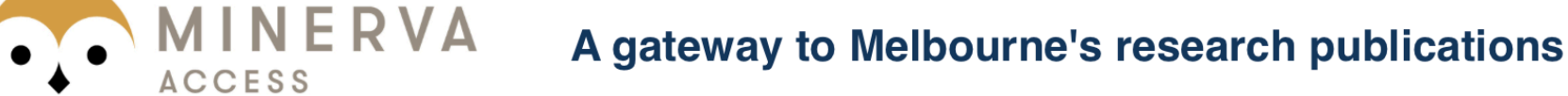

Minerva Access is the Institutional Repository of The University of Melbourne

Author/s:

Rajabifard, A.;Binns, A.;Masser, I.;Williamson, I. P.

Title:

The role of sub-national government and the private sector in future Spatial Data Infrastructures

Date:

2006-08

Citation:

Rajabifard, A. and Binns, A. and Masser, I., \& Williamson, I. P. (2006). The role of sub-national government and the private sector in future Spatial Data Infrastructures. International Journal of Geographical Information Science, 20(7), 727-741.

Publication Status:

Published

Persistent Link:

http://hdl.handle.net/11343/34922 